Erratum

\title{
A new oxygen-regulated operon in Escherichia coli comprises the genes for a putative third cytochrome oxidase and for $\mathrm{pH} 2.5$ acid phosphatase (appA)
}

\author{
Janie Dassa $^{1}$, Hafida Fsihi ${ }^{1}$, Christian Marck ${ }^{2}$, Michel Dion ${ }^{1}$, Muriel Kieffer-Bontemps ${ }^{1}$, and Paul L. Bouquet ${ }^{1}$
}

${ }^{1}$ Service de Biochimie des Proteines, Laboratoire d'Ingénierie des Proteines, and ${ }^{2}$ Service de Biochimie et Génétique Moléculaire. C.E. Saclay, F-91191 Gif-sur-Yvette Cédex, France

Mol Gen Genet (1991) 229:341-352

Due to an error in selection of prints, the gel shown in Fig. $6 \mathrm{~A}$ of this article does not correspond to the described experiment (initiation at app $\mathrm{P} 1$ promoter). The correct figure is given below.
Furthermore, the last sentence in the legend to Fig. 7, should read: Histidine residues are underlined.

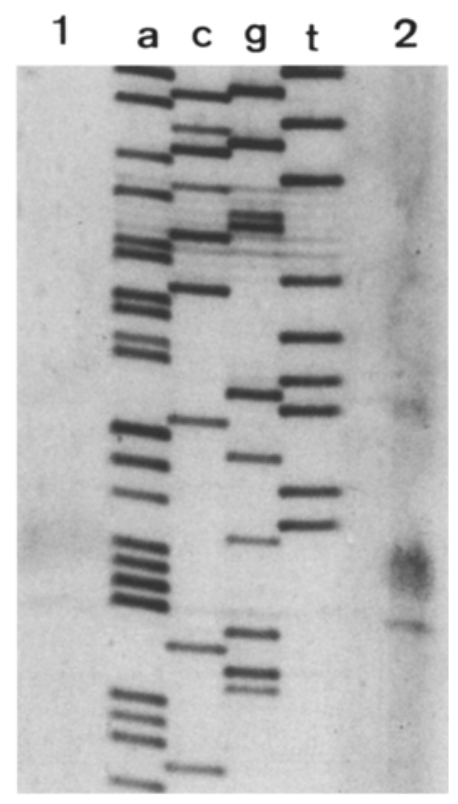

A

Abb. 6A 